\title{
Mucormycosis: Post Covid-19 Fungal Infection
}

\author{
Souvik Tewari ${ }^{1}$, John David ${ }^{1}$, Swati Nakhale $^{2 *}$ and Bipasha David ${ }^{3}$ \\ ${ }^{1}$ Department of Food Science and Technology, WCDT, SHUATS, Allahabad, U.P., India \\ ${ }^{2}$ IIFST, Aurangabad, Maharashtra, India \\ ${ }^{3}$ Department of A.H. and Dairying, Naini Agricultural Institute, SHUATS, U.P., India \\ *Corresponding author
}

Keywords

Coronavirus infection, Post

Covid-19,

Mucormycosis,

fungal infection,

immune boosting

foods,

rhinocerebral,

pulmonary (lung),

Cutaneous

mucormycosis,

gastrointestinal

mucormycosis,

disseminated

mucormycosis

Article Info

Accepted:

12 May 2021

Available Online:

10 June 2021

\section{A B S T R A C T}

Coronavirus primarily affects the human immune system and weakens it. As a result, even after recovering from this infection, the patient's immune system is insufficient to protect him from other infections such as bacterial and fungal infections. One of the post Covid-19 infection is mucormycosis. Mucormycosis is a fungal infection caused by fungi that belongs to the Mucorales family. These funguses can be found in soil, as well as decaying organic matter such as leaves, compost piles, and rotting wood. Every day, everyone is exposed to millions of fungal spores. Safe people, on the other hand, have a strong immune system to support them. However, since the patient's immune system is weakened during Covid-19, many fungal infections spread quickly after the infection. Mucormycosis is a common fungal infection that affects people who have already been diagnosed with Covid-19 or after Covid-19. Mucormycosis is a disease that is relatively rare. The infection is more common in people with weakened immune systems, but it can also strike otherwise healthy people on rare occasions. There are several different immune-boosting foods to choose from, each of which helps to boost immunity and fight various virus infections after Covid-19 infections. Protein-rich foods, omega-3 fatty acid-rich foods, high antioxidant-rich foods and the most important pharma-therapeutic foods like garlic, turmeric, and green tea should be taken during post Covid-19 infections.

\section{Introduction}

Now a days all over the world the people are trying to protect the spreading of coronavirus infection. The coronavirus was first appearing in China in 2019, after that approximately all countries are affected from this infection. Coronavirus mainly effects in human immune 
system and decrease immune power. So after recovering from this infection, patient does not have proper immune power to protect other infections like bacterial and fungal infection. Mucormycosis is the one of them which effects after Covid-19 infection.

\section{Mucormycosis}

Mucormycosis is a fungal infection caused by fungi in the Mucorales order (Hibbett et al., 2007). Mucormycosis (also known as zygomycosis) is a rare fungal infection caused by Mucoromycotina fungus species.

Zygomycota was the previous scientific name for these fungi, but it is recently revised. These fungi can be present in the soil as well as in decaying organic matter like leaves, compost piles, and rotten wood.

Mucormycosis is characterized by the presence of hyphal invasion of sinus tissue and a time course of less than four weeks (Ferguson, 2000); (Chakrabarti et al., 2009).

\section{Risk factors of Mucormycosis}

Uncontrolled diabetes mellitus in ketoacidosis, other forms of metabolic acidosis, corticosteroid treatment, organ or bone marrow transplantation, neutropenia, trauma and burns, malignant hematologic disorders, and deferoxamine therapy in hemodialysis patients are all major risk factors for mucormycosis (Spellberg et al., 2005); (Sugar, 1992); (Ibrahim et al., 2003).

The number of patients at risk for this deadly infection is significantly growing due to the rising prevalence of diabetes mellitus, cancer, and organ transplantation in the aging US population (Marr et al., 2002).

The overall mortality rate for mucormycosis remains about $50 \%$, and it exceeds $100 \%$ in patients with disseminated disease or chronic neutropenia (Spellberg et al., 2005); (Gleissner et al., 2004). New strategies to prevent and treat mucormycosis are clearly needed, and such strategies can be aided by a thorough understanding of the disease's pathogenesis.

\section{Sign and Symptoms of Mucormycosis}

Sign and Symptoms normally manifest first in the infected body region and include the following (David, 2021):

Fever,

Headache,

Reddish and swollen skin over nose and sinuses,

Eye(s) swelling,

Facial pain,

Dark scabbing in the nose by eye(s),

Visual problems,

shortness of breath,

Diffuse abdominal pain,

Coughing sometimes with bloody or dark fluid production,

Flank pain,

Bloody and sometimes dark vomitus,

Abdominal distension,

An ulcer with a dark center and sharply defined edges, and

Mental-status changes may occur. 


\section{Covid-19 and Mucormycosis}

Normally all people are exposed to millions of fungal day to day. But healthy people have good immune power to protect them. But due to decrease immune power of patient during Covid-19, many fungal infections effects easily after Covid-19 infections. Mucormycosis fungal infection is one of most important fugal that effects to people who are already suffered from Covid-19. Mucormycosis is a relatively uncommon infection. The infection is more common in people who have compromised immune systems, but it can also happen (rarely) in otherwise healthy people.

\section{Symptoms of Mucormycosis}

The symptoms of mucormycosis differ depending on where the fungus has taken hold in the body.

\section{Symptoms of rhinocerebral (sinus and brain) mucormycosis include}

Saprophytic fungi cause rhinocerebral mucormycosis, a rare opportunistic infection of the sinuses, nasal passages, oral cavity, and brain. The infection has the potential to kill you quickly. Rhinocerebral mucormycosis is a fungal infection that affects people with diabetes and others that are immunocompromised (Gilbard \& Della Rocca, 1998); (Petrikkos et al., 2012); (Gamalets et al., 2012). Clinically, rhinocerebral mucormycosis can present with atypical signs and symptoms similar to complicated sinusitis, such as nasal blockade, crusting, proptosis, facial pain and oedema, ptosis, chemosis, and even ophthalmoplegia, with headache and fever and various neurological signs and symptoms if intracranial extension is present (Scheckenbach et al., 2010); (Vairaktaris et al., 2009).
Fever

Headache

Nasal or sinus congestion

One-sided facial swelling

Black lesions on nasal bridge or upper inside of mouth that quickly become more severe

\section{Symptoms of pulmonary (lung) mucormycosis include}

Fever

Cough

Shortness of breath

Chest pain

\section{Symptoms of cutaneous mucormycosis}

Symptoms of cutaneous mucormycosis appears as blisters or ulcers on the skin, and the infected area can turn black. Pressure, warmth, constant redness, and swelling around a wound are some of the other symptoms.

\section{Symptoms of gastrointestinal mucormycosis include}

Abdominal pain

Nausea and vomiting

Gastrointestinal bleeding

\section{Symptoms of disseminated mucormycosis}

Since disseminated mucormycosis usually affects people who are already sick from other illnesses, determining which symptoms are linked to mucormycosis can be difficult. 
Fig.1 Rhinocerebral (sinus and brain) mucormycosis (Source: Therakathu et al., 2018)

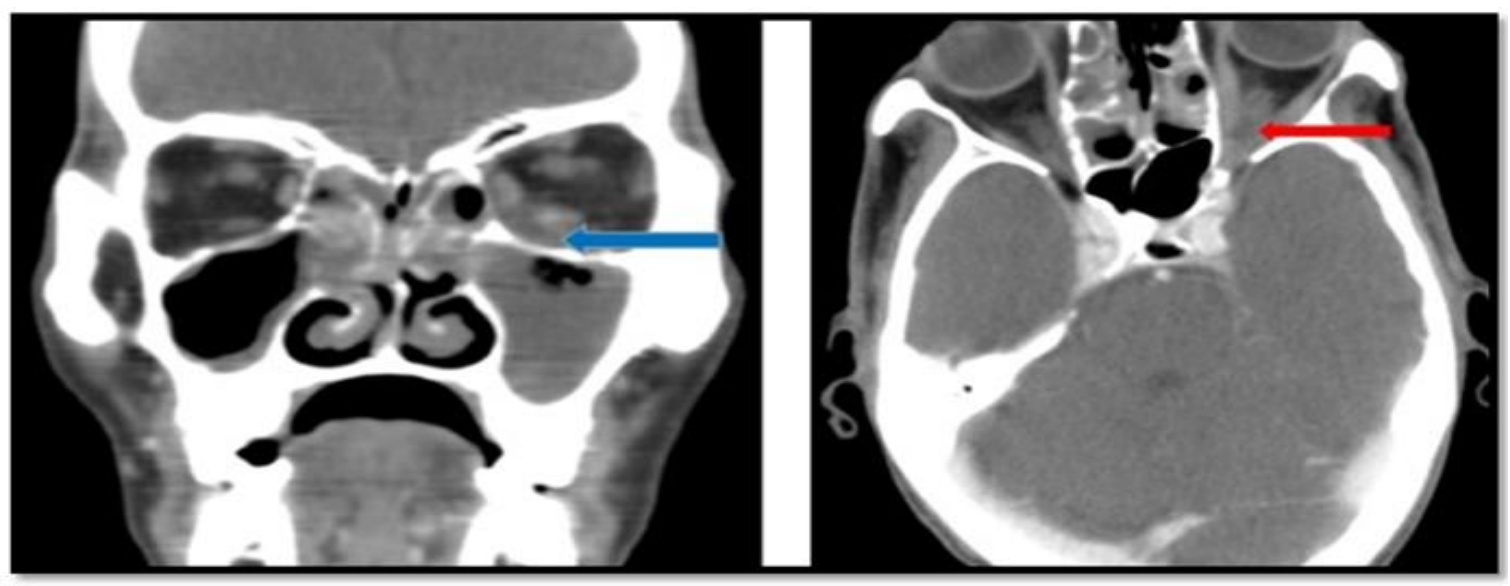

Fig.2 Pulmonary (lung) mucormycosis (Source: Fernandez et al., 2013)

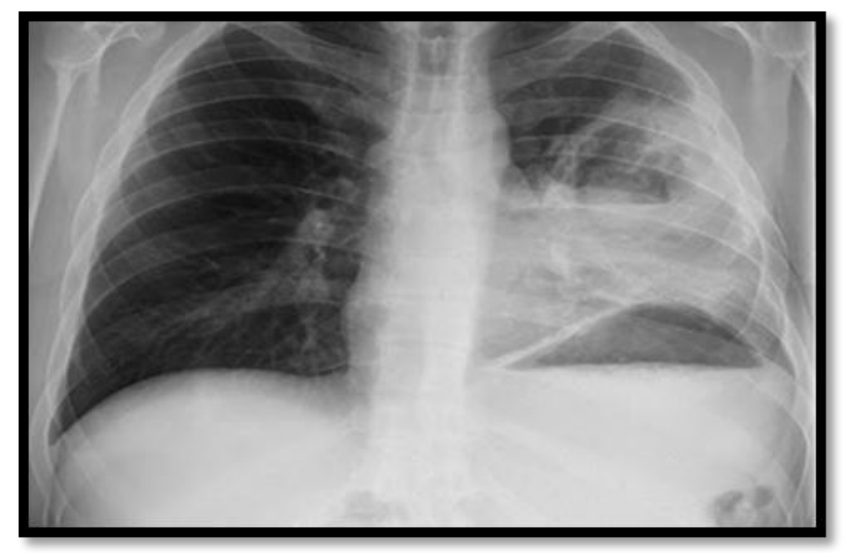

Fig.3 Cutaneous mucormycosis (Source: Cox, et al., 2011)

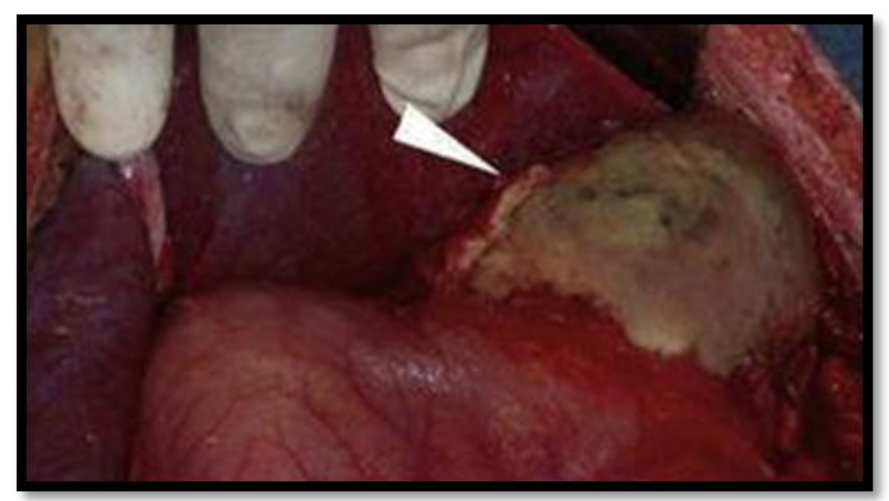


Fig.4 Gastrointestinal mucormycosis (Source: Alvarado-Lezama et al., 2015)

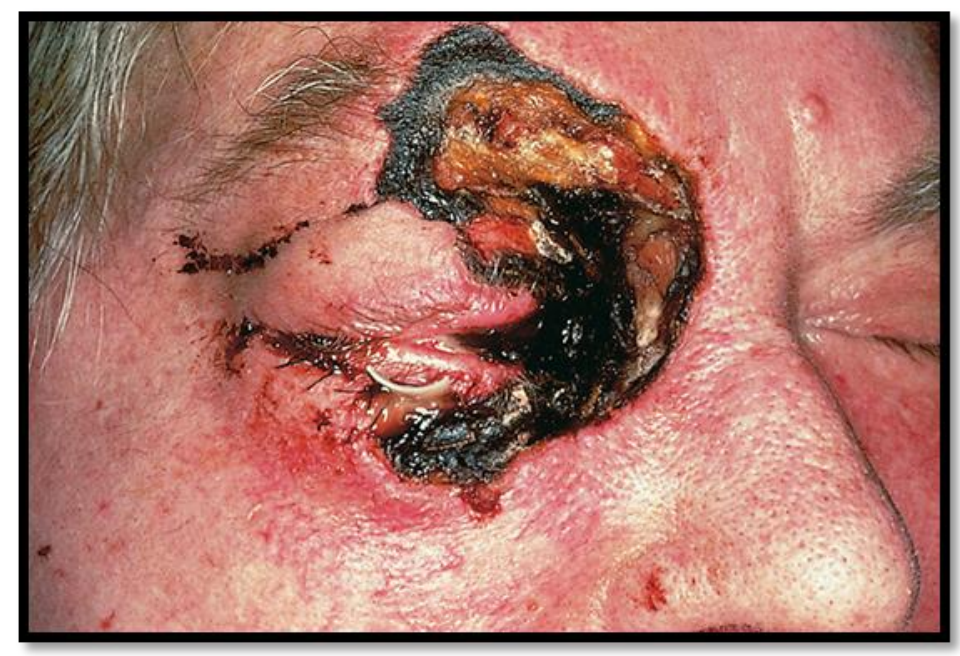

Fig.5 Disseminated mucormycosis (Source: Campbell et al., 2014)

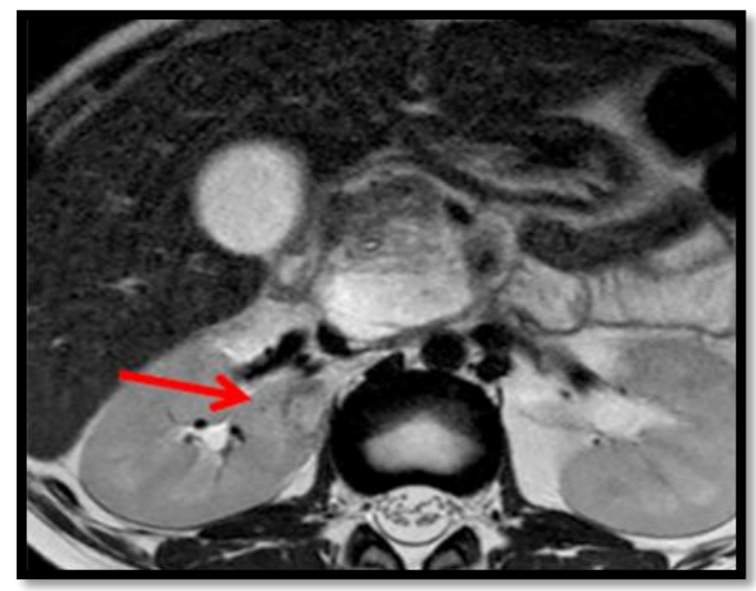

Mental state changes or coma may occur in patients with a disseminated infection in the brain (Lewis and Kontoyiannis, 2013); (Spellberg et al., 2005); (Ribes et al., 2000).

\section{Pharma-therapeutic diet against post covid infection}

There are a variety of immune-boosting foods to choose from, each of which aids in the increase of immunity and the battle against various virus infections. Protein rich food, omega-3 fatty acid rich foods, high antioxidant rich food, Garlic, turmeric, green tea are the most essential pharma-therapeutic foods.

\section{Protein rich foods}

Milk, eggs, tofu, tempeh, and fish are all full proteins that aid in immunity maintenance. Antioxidants are abundant in broccoli, spinach, and carrots, which are useful in this pandemic situation.

\section{High Omega-3 fatty acid rich foods}

Foods high in omega-3 fatty acids improve immunity. Coldwater fish such as salmon, mackerel, sardines, and tuna are high in omega-3. 
Highly anti-oxidant rich fruits and Green tea and its potential health benefits vegetables

Vegetables and fruits are excellent sources of vitamins, minerals, and fiber for humans. They differ in several ways, including vitamin, mineral, and fiber content, as well as antioxidant potential.

Fruits are noted for being high in antioxidants such as ascorbic acid, carotenoids, and phenolics (Arshiya, 2013).

According to some research, the antioxidants present in some fruits and vegetables have a high bioavailability (Parashar et al., 2008).

Antioxidants can also be found in abundance in a variety of fruits and vegetables. It's likely that increasing your intake of these fruits will increase your intake of natural antioxidants, which can help slow down the aging process by shielding you from oxidative harm.

\section{Garlic and its immunomodulatory properties}

Garlic (Allium sativum) is one of the best immune-boosting spices available. Garlic has antimicrobial properties as well as antiinflammatory properties. Garlic has recently gained popularity as an immunomodulatory spice. Immunomodulators are drugs that help the immune system to function properly.

Several studies in animal models have been conducted to investigate the impact of garlic compound as an immunomodulator (Arreola, et al., 2015).

Various experiments have been conducted to determine the effects of garlic compounds on immune system cells, and these studies have discovered that garlic compounds can preserve immunity through their immunomodulatory activities (Bauer, et al., 2014; Park, et al., 2014).
The health benefits of green tea are physiological and pharmacological. According to Steinmann et al., (2013), the key ingredient of green tea is epigallocatechin-3-gallate (EGCG), which has anti-infective and antiviral properties and can help control infection and other viral fevers. EGCG catechine also has antifungal action against human pathogenic yeasts including Candida albicans. Although the mechanism of EGCG's effects is unknown, findings indicate that it binds to lipid membranes and influences folic acid metabolism in bacteria and fungi by inhibiting the cytoplasmic enzyme dihydrofolate reductase.

Green tea contains the compound Epigallocatechin-3-gallate (EGCG), which has anti-chikungunya virus properties, according to Lee et al., (2012). Chikungunya fever is caused by an alphavirus that is spread from person to person. Green tea also has antiviral effects, which can help prevent viral infection and fever, according to the researchers.

\section{References}

Alvarado-Lezama, J., Espinosa-González, O., García-Cano, E., \& Sánchez-Córdova, G. (2015). Emphysematous gastritis secondary to gastric mucormycosis. Cirugía y Cirujanos (English Edition), 83(1), 56-60.

Arreola R, Quintero-Fabián S, López-Roa R I, Flores-Gutiérrez E O, Reyes-Grajeda J $\mathrm{P}$, Carrera-Quintanar L, OrtuñoSahagún D. Immunomodulation and anti-inflammatory effects of garlic compounds. Journal of immunology research. 2015; 13.

Arshiya S. The antioxidant effect of certain fruits:-A review. Journal of Pharmaceutical Sciences and Research. 2013; 5(12):265. 
Bauer D, Mazzio E, Soliman K F, Taka E, Oriaku E, Womble T, Darling-Reed S. Diallyl disulfide inhibits TNF $\alpha$ induced CCL2 release by MDA-MB231 cells. Anticancer research. 2014; 34(6):2763-70.

Campbell, A., Cooper, C., \& Davis, S. (2014). Disseminated mucormycosis in a paediatric patient: Lichtheimia corymbifera successfully treated with combination antifungal therapy. Medical mycology case reports, 6, 1821.

Chakrabarti, A., Denning, D. W., Ferguson, B. J., Ponikau, J., Buzina, W., Kita, H., \& Radotra, B. D. (2009). Fungal rhinosinusitis: a categorization and definitional schema addressing current controversies. The Laryngoscope, 119(9), 1809-1818.

Charles Patrick David, MD, PhD Medical Editor: Mary D. Nettleman, MD, MS, MACP Medically Reviewed on 5/10/2021.

Cox, G. M., Kauffman, C., \& Thorner, A. (2011). Mucormycosis (zygomycosis). Trauma, 34, 36.

Ferguson, B. J. (2000). Definitions of fungal rhinosinusitis. Otolaryngologic clinics of north America, 33(2), 227-235.

Fernandez, J. F., Maselli, D. J., Simpson, T., \& Restrepo, M. I. (2013). Pulmonary mucormycosis: what is the best strategy for therapy?. Respiratory care, 58(5), e60-e63.

Gamalets, ou M. N., Sipsas, N. V., Roilides, E., \& Walsh, T.J. (2012). Rhinoorbital-cerebral mucormycosis. Curr Infect Dis Rep. 14 (4): 423-34.

Gilbard, S. M., \& Della Rocca, R. C. (1998) Smith's Ophthalmic Plastic and Reconstructive Surgery. Nesi FA, et al., eds Paranasal sinus disease and the orbit. $2^{\text {nd }}$ ed. 896-930.

Gleissner, B., Schilling, A., Anagnostopolous, I., Siehl, I., \& Thiel, E. (2004).
Improved outcome of zygomycosis in patients with hematological diseases?. Leukemia \& lymphoma, 45(7), 13511360.

Hibbett, D. S., Binder, M., Bischoff, J. F., Blackwell, M., Cannon, P. F., Eriksson, O. E., \& Zhang, N. (2007). A higher-level phylogenetic classification of the Fungi. Mycological research, 111(5), 509-547.

Ibrahim, A. S., Edwards, J. E. J., \& Filler, S. G. (2003). Zygomycosis. 241-251. Clinical mycology. Oxford University Press, New York, NY.

Lee H J, Lee Y N, Youn H N, Lee D H, Kwak J H, Seong B L, Lee J B, Park S Y, Choi I S, Song C S. Anti-influenza virus activity of green tea by-products in vitro and efficacy against influenza virus infection in chickens. Poultry science. 2012; 91(1):66-73.

Lewis, R. E., \& Kontoyiannis, D. P. (2013). Epidemiology and treatment of mucormycosis. Future microbiology, 8(9), 1163-1175.

Marr, K. A., Carter, R. A., Crippa, F., Wald, A., \& Corey, L. (2002). Epidemiology and outcome of mould infections in hematopoietic stem cell transplant recipients. Clinical Infectious Diseases, 34(7), 909-917.

Parashar A, Gupta S K, Kumar A. Anthocyanin concentration of KANDARI Pomegranate fruits during different cold storage conditions. ACI, XXXIV C. 2008; 3:529-536.

Park S Y, Seetharaman R, Ko M J, Kim T H, Yoon M K, Kwak J H, Lee S J, Bae Y $\mathrm{S}$, Choi $\mathrm{Y}$ W. Ethyl linoleate from garlic attenuates lipopolysaccharideinduced pro-inflammatory cytokine production by inducing heme oxygenase-1 in RAW264. 7 cells. International Immunopharmacology. 2014; 19(2):253-61. 
Petrikkos, G., Skiada, A., Lortholary, O., Roilides, E., Walsh, T. J., \& Kontoyiannis, D. P. (2012). Epidemiology and clinical manifestations of mucormycosis. Clinical Infectious Diseases, 54(suppl_1), S23-S34.

Ribes, J. A., Vanover-Sams, C. L., \& Baker, D. J. (2000). Zygomycetes in human disease. Clinical microbiology reviews, 13(2), 236-301.

Scheckenbach, K., Cornely, O., Hoffmann, T. K., Engers, R., Bier, H., Chaker, A., \& Wagenmann, M. (2010). Emerging therapeutic options in fulminant invasive rhinocerebral mucormycosis. Auris Nasus Larynx, 37(3), 322-328.

Spellberg, B., Edwards, J., \& Ibrahim, A. (2005). Novel perspectives on mucormycosis: pathophysiology, presentation, and management. Clinical Microbiology Reviews, 18(3), 556-569.
Steinmann J, Buer J, Pietschmann T, Steinmann E. Anti infective properties of epigallocatechin 3 gallate (EGCG), a component of green tea. British journal of pharmacology. 2013; 168(5):1059-73.

Sugar, A. M. (1992). Mucormycosis. Clinical Infectious Diseases, 14 (Supplement_1), S126-S129.

Therakathu, J., Prabhu, S., Irodi, A., Sudhakar, S. V., Yadav, V. K., \& Rupa, V. (2018). Imaging features of rhinocerebral mucormycosis: A study of 43 patients. The Egyptian Journal of Radiology and Nuclear Medicine, 49(2), 447-452.

Vairaktaris, E., Moschos, M. M., Vassiliou, S., Baltatzis, S., Kalimeras, E., Avgoustidis, D., \& Moschos, M. N. (2009). Orbital cellulitis, orbital subperiosteal and intraorbital abscess. Report of three cases and review of the literature. Journal of Craniomaxillofacial surgery, 37(3), 132-136.

\section{How to cite this article:}

Souvik Tewari, John David, Swati Nakhale and Bipasha David. 2021. Mucormycosis: Post Covid-19 Fungal Infection. Int.J.Curr.Microbiol.App.Sci. 10(06): 64-71. doi: https://doi.org/10.20546/ijcmas.2021.1006.006 